\title{
The little nipper who cost the South a fortune
}

Colin Norman reports on a threat to call $a$ halt to a long and largely unsuccessful attempt to eradicate the fire ant.

THIS is an account of a fruitless attempt to block an invasion, of political manoeuvrings and fiscal blackmail, of chemical warfare and environmental destruction, and of open dispute between two factions in the federal government. Underlying the whole sorry affair are a variety of scientific issues, but they have generally taken a back seat.

The invasion began in 1918 when a small black ant, known as Solenopsis richteri', established a colony near Mobile, Alabama, after hitching a ride on a shipment of fruit from South America. Since then the ant and its red cousin Solenopsis invicta has invaded nine states from Texas to North Carolina, resisted a fearful onslaught of insecticides, soaked up $\$ 115$ million in public money and stirred up a massive controversy.

For the past 18 years, the Department of Agriculture, in concert with the infested states, has been attacking the ants with a variety of chemicals, with the result that the programme has the dubious distinction of being the most expensive single pest-control effort ever carried out in the United States. But last month, Earl Butz, the Secretary of Agriculture, announced that the federal government is finally cutting its losses and will cease bombarding the ants with pesticides on June 30 .

The announcement is probably more of a threat than a promise, however, for Butz's statement seems designed to bring political pressure to bear on the Environmental Protection Agency (EPA) to lift restrictions on the pesticide used to attack the ant. "Continuing restrictions placed on the pesticide", But $z$ said, "have finally made the program completely unworkable", and for good measure he added that the ants "could be totally eradicated with only negligible effects on the environment" if only the EPA were not so diligent in enforcing its regulations.

Officials of the EPA were clearly caught by surprise, for in 1971 the Department of Agriculture decided that for various reasons, including cost, a programme to eradicate the ants was no longer feasible. Future efforts would therefore be aimed at preventing the pest from spreading, the Department said. Nevertheless, Butz's statement has already promoted an outcry in the deep South, and some powerful southern Democrats are beginning to ask questions on Capitol Hill. The battle, clearly, is far from over.

Why has this insect provoked such a costly and seemingly futile campaign? The chief reason is that it has a nasty habit of attacking anybody who comes near it, inflicting a painful sting for which the creature has earned the name of 'fire ant'. It also builds mounds, sometimes reaching a height of about 3 feet, which have hard crusts and present a hazard to farm implements.

About 10,000 people a year were treated in Alabama, Georgia and Mississippi for fire-ant stings in 196971. Secondary infections and allergic reactions are the most common problems, although there have only been one or two reports of death from severe allergic reactions-in that respect, the ant is much less of a problem than wasps or bees. A committee which studied the fire-ant problem in 1972 reported that it is "of virtually no importance as a primary pest of crops, livestock or cattle" and in fact it may in some instances be helpful in killing off crop pests. The committee said, however, that the fire ant can harm agriculture by stinging farmworkers, to the extent that they will sometimes refuse to work in heavily infested fields.

The fire ant is clearly a great nuisance, but whether it merits a full scale chemical assault is, however, another matter. In any case, in view of the failure of past efforts to control the ant's spread, Butz's decision to terminate the programme seems like a prudent financial decision at a time when the Ford Administration is trying to reduce public expenditures.

The invasion began slowly at first, encompassing only about 2,000 acres by 1932 . In the next 15 years, however, the fire ant had spread to about 2 million acres and by 1959 its territory had widened to 26 million acres. The federal government and the states began their effort to combat the ant in 1957 , but the insect promptly responded by expanding its territory to 126 million acres between 1959 and 1969, which makes the anti-invasion strategy about as effective as the federal government's containment activities on the other side of the world. And, like the generals in Vietnam, the field commanders in the fire-ant programme were constantly promising that the end would soon be in sight.

In the early stages, heptachlor and dieldrin were used to bombard the fire ant at a cost of some $\$ 2$ million a year to the federal government; a similar amount was supplied by the treasuries of the southern states. But, in 1962, the campaign switched to a new weapon-a chlorinated hydrocarbon called Mirex which was reckoned to create fewer environmental hazards and to be more effective than the other pesticides.

Described in one report as having "many of the requirements for an ideal control chemical for the ant", Mirex is applied in very small amounts-about $1.7 \mathrm{~g}$ per acre-dissolved in soyabean oil and spread on corn-cob grits. The grits are dropped on to infested fields by aircraft, and are taken up by foraging ants which carry the pesticide back into the mound, where the poison eventually wipes out the entire colony.

Although there had been a few attempts within the federal government to bring a halt to the fire-ant programme during the mid-1960s, the first major challenge came in 1970 in the form of a court suit brought by the Environmental Defense Fund (EDF), a Washington-based environmental organisation. Following reports that Mirex residues had turned up in a wide variety of organisms, particularly crustaceans and other aquatic wildlife, the EDF brought a suit to halt the programme. The immediate result was that on March 17, 1971 the EPA notified the manufacturer of Mirex-the Allied Chemical Corporation-of its intent to cancel registration of the pesticide. That first formal step to remove the chemical from the market was designed chiefly to open up a long investigation of Mirex, which was still going on when the Department of Agriculture made its announcement last month.

The first stage in the investigation was the appointment of a scientific advisory committee, which recommended to the EPA in 1972 that use of Mirex be continued to control the ants. The committee said, however, that the programme should not be aimed at eradication because "the environmental impact of such treatment is too poorly understood and the expense too great to justify a program of such magnitude". The EPA, therefore, decided to prevent the use of Mirex in coastal areas, heavily wooded areas and near inland waters. It also limited use of the pesticide to one application a year. Finally, the EPA began public hearings on the environmental impact of the programme in 1973, and those have been going on intermittently for the past fifteen months. 
Although the EPA's regulations merely reflected what the Department of Agriculture was already doing in 1973, it was those restrictions which Butz condemned last month for crippling the fire-ant programme.

Why has the effort dragged on for so long, in spite of little success? The answer lies partly in the complicated politics of the deep South. For one thing, the $\$ 68$ million that the federal government has so far pumped in to the programme (which has been augmented by $\$ 47$ million from the states themselves) has provided a welcome addition to the coffers of state agriculture departments. And for another, the programme has powerful supporters in Washington, notably Jamie Whitten, chairman of the House appropriations subcommittee which handles the budget of the Department of Agriculture, and J. Phil Campbell, the Under Secretary of Agriculture. Whitten comes from Mississippi and Campbell comes from Georgia, both of which are heavily infested with fire ants.

Whitten's support for the programme in fact twice saved it from the axe in the mid-1960s, when the Bureau of the Budget tried to eliminate it. Whitten was furious and eventually increased the budget for the programme instead of eliminating it. By 1974, federal funding had passed the \$7-million-a-year mark, and the Administration had asked for $\$ 9$ million for the next year.

The EPA's surprise at Butz's decision to pull out of the fire-ant programme is evident from a letter sent to Butz by John Quarles, Deputy EPA Administrator, a few days after the announcement
About 10,000 people a year were treated in Alabama, Georgia and Mississippi for fire-ant stings in 1969-71. Secondary infections and allergic reactions are the most common problems although there have only been one or two reports of death from severe allergic reactions.

was made. Noting that the Department of Agriculture had "abandoned the concept of eradicating the fire ant prior to the imposition of EPA restrictions on the advice of scientists that this effort would be financially and logistically infeasible", Quarles said that the announcement "tends to bring undeserved criticism to [the EPA] when other considerations appear to have played a larger role" in the decision to terminate the programme.

Replying to the letter, Under Secretary Campbell said that "we have chosen to exercise our prerogatives responsibly by suspending the program until we can operate free of crippling restrictions. We ask that, as you exercise your responsibility, you take into consideration that to be environmentally sound, the program must eliminate the fire ant as a pest"

Asked last week what would be required to eliminate the fire ant entirely, scientists at the Department of Agriculture said it would probably take three applications of Mirex in an eighteen-month period over the entire infested area, including coastal regions. Since the federal government last year spent about $\$ 1$ per acre on the programme, complete eradication would run into hundreds of millions of dollars.

The department's belief that eradication is possible is based on three largescale trials carried out in Georgia, Florida and Mississippi in 1967, where almost total eradication of the ant was achieved after three applications of Mirex. Opponents of the programme point out, however, that the areas rapidly became reinfested, and that if such a programme is carried out on a larger area, the potential destruction of non-target species would be very large.

Nevertheless, Butz's decision has been greeted with dismay in the infested states, which have been relying on federal support for their efforts to control the ant. Typical of such reaction is a letter sent by the commissioner of Alabama State Department of Agriculture to Representative William $L$. Dickinson. "To deprive the inhabitants of the infested states of the program which gives some relief from the Imported Fire Ant is reprehensive [sic]", the letter stated.

It is unlikely that the plea will go unheeded in Congress, but exactly what will transpire is, at this stage, highly uncertain.

Shaded area: generally infested area (eradication treatments not in progress or planned). Hatched areas: ant eradicated, and regulations removed.

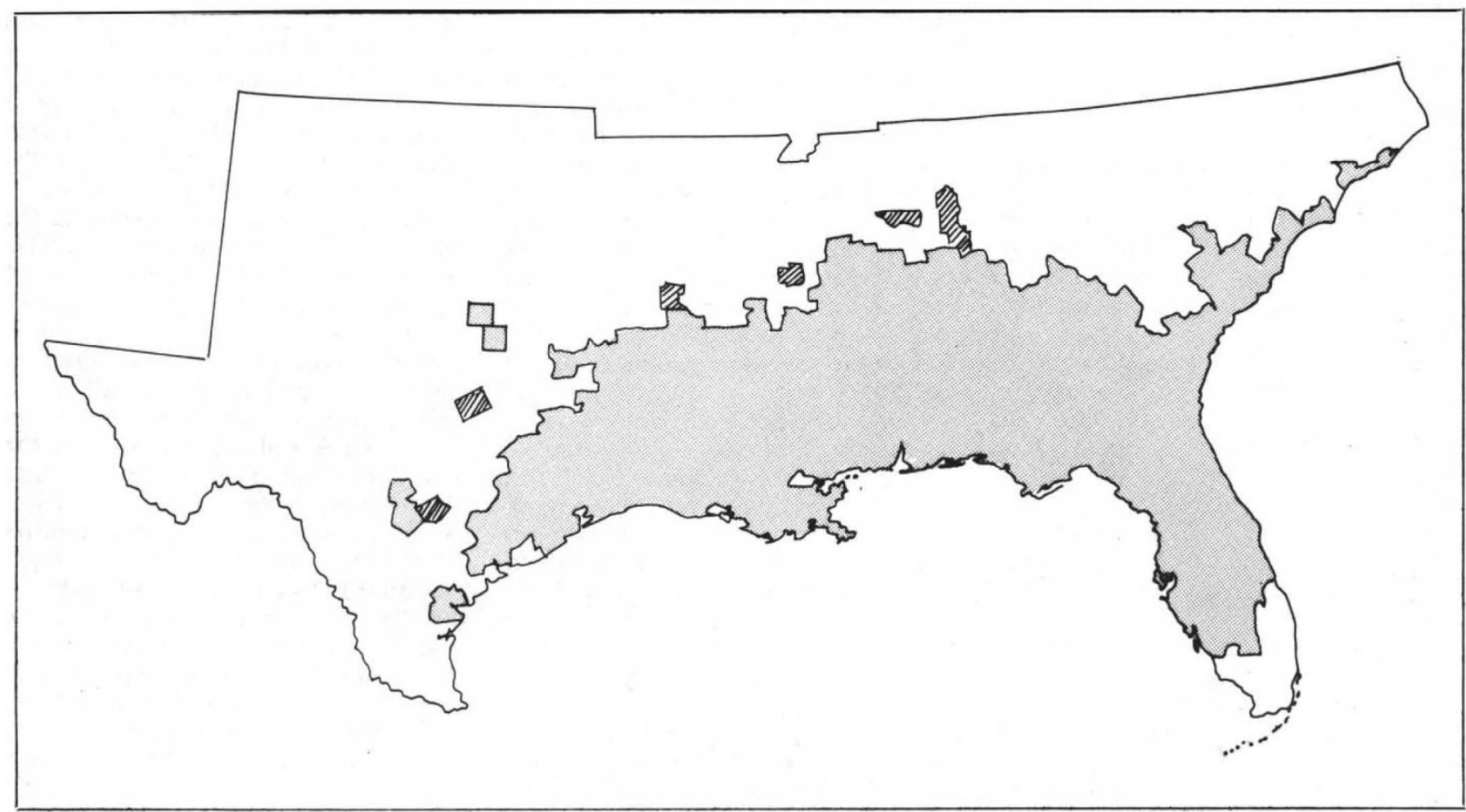

